\title{
FIXED POINT THEOREMS FOR NON-SELF MAPS IN d-COMPLETE TOPOLOGICAL SPACES
}

\section{LINDA MARIE SALIGA}

Department of Mathematical Sciences

The University of Akron

Akron, Ohio 44325-4002 USA

(Received July 7, 1994 and in revised form August 8, 1994)

\begin{abstract}
Fixed point theorems are given for non-self maps and pairs of non-self maps defined on d-complete topological spaces.
\end{abstract}

KEY WORDS AND PHRASES. d-complete topological spaces, fixed points, non-self maps, pairs of mappings.

1991 SUBJECT CLASSIFICATION CODE. 47H10, 54H25.

\section{INTRODUCTION.}

Let $(X, t)$ be a topological space and $d: X \times X \rightarrow[0, \infty)$ such that $d(x, y)=0$ if and only if $\mathrm{x}=\mathrm{y}$. $\quad \mathrm{X}$ is said to be $\mathrm{d}$-complete if $\sum_{n=1}^{\infty} \mathrm{d}\left(\mathrm{x}_{n}, \mathrm{x}_{n+1}\right)<\infty$ implies that the sequence $\left\{x_{n}\right\}_{n=1}^{\infty}$ is convergent in $(X, t)$. Complete metric spaces and complete quasi-metric spaces are examples of $d$-complete topological spaces. The d-complete semi-metric spaces form an important class of examples of d-complete topological spaces.

Let $\mathrm{X}$ be an infinite set and $t$ any $T_{1}$ non-discrete first countable topology for $X$. There exists a complete metric $d$ for $X$ such that $t \leq t_{d}$ and the metric topology $t_{d}$ is non-discrete. Now $(\mathrm{X}, \mathrm{t}, \mathrm{d})$ is d-complete since $\sum_{n=1}^{\infty} \mathrm{d}\left(\mathrm{x}_{n}, \mathrm{x}_{n+1}\right)<\infty$ implies that $\left\{\mathrm{x}_{n}\right\}_{n=1}^{\infty}$ is Cauchy in $\mathrm{t}_{d}$. Thus, $x_{n} \rightarrow x$, as $n \rightarrow \infty$, in $t_{d}$ and therefore in the topology $t$. The construction of $t_{d}$ is given by T. L. Hicks and W. R. Crisler in [1].

Recently, T. L. Hicks in [2] and T. L. Hicks and B. E. Rhoades in [3] and [4] proved several metric space fixed point theorems in $d$-complete topological spaces. We shall prove additional theorems in this setting.

Let $\mathrm{T}: \mathrm{X} \rightarrow \mathrm{X}$ be a mapping. $\mathrm{T}$ is $\omega$-continuous at $\mathrm{x}$ if $\mathrm{x}_{n} \rightarrow \mathrm{x}$ implies $\mathrm{Tx}_{n} \rightarrow \mathrm{Tx}$ as $\mathrm{n} \rightarrow \infty$. A real-valued function $G: X \rightarrow[0, \infty)$ is lower semi-continuous if and only if $\left\{x_{n}\right\}_{n=0}^{\infty}$ is a sequence in $X$ and $\lim _{n \rightarrow \infty} x_{n}=p$ implies $G(p) \leq \lim _{n \rightarrow \infty} \inf \left(x_{n}\right)$.

\section{RESULTS.}

In [2], Hicks gave the following result.

THEOREM ([2], Theorem 2): Suppose $X$ is a d-complete Hausdorff topological space, $\mathrm{T}: \mathrm{X} \rightarrow \mathrm{X}$ is $\omega$-continuous and satisfies $\mathrm{d}\left(\mathrm{T} x, \mathrm{~T}^{2} \mathrm{x}\right) \leq k(\mathrm{~d}(\mathrm{x}, \mathrm{T} \mathrm{x}))$ for all $\mathrm{x} \in \mathrm{X}$, where $k:[0, \infty) \rightarrow[0, \infty), k(0)=0$, and $k$ is non-decreasing. Then $\mathrm{T}$ has a fixed point if and only if 
there exists $\mathrm{x}$ in $\mathrm{X}$ with $\sum_{n=1}^{x} k^{n}(\mathrm{~d}(\mathrm{x}, \mathrm{T} \mathrm{x}))<\infty$. In this (ase, $\mathrm{x}_{n}=\mathrm{T}^{n} \mathrm{x} \rightarrow \mathrm{p}=\mathrm{T}$ ). $\quad(k$ is not assumed to be continuous and $k:(a)=k(k(a))$.]

The following conditions are examined. Let $\mathrm{T}: \mathrm{C} \rightarrow \mathrm{X}$ with $\mathrm{C}$ a closed subset of the $\mathrm{d}-$ complete topological space $\mathrm{X}$ and $\mathrm{C} \subset \mathrm{T}(\mathrm{C})$. Let $k:[0, \infty) \rightarrow[0, \infty)$ be such that $k(0)=0, k$ is non-decreasing. and

$$
k(\mathrm{~d}(\mathrm{Tx}, \mathrm{Ty})) \geq \mathrm{d}(\mathrm{x}, \mathrm{y})
$$

for all $\mathrm{x}, \mathrm{y} \in \mathrm{C}$, or

$$
\mathrm{d}(\mathrm{Tx}, \mathrm{Ty}) \geq k(\mathrm{~d}(\mathrm{x}, \mathrm{y}))
$$

for all $\mathrm{x}, \mathrm{y} \in \mathrm{C}$, or

$$
\mathrm{d}(\mathrm{x}, \mathrm{y}) \geq k(\mathrm{~d}(\mathrm{Tx}, \mathrm{Ty}))
$$

for all $\mathrm{x}, \mathrm{y} \in \mathrm{C}$, or

$$
k(\mathrm{~d}(\mathrm{x}, \mathrm{y})) \geq \mathrm{d}(\mathrm{Tx}, \mathrm{Ty})
$$

for all $\mathrm{x}, \mathrm{y} \in \mathrm{C}$.

It will be shown that condition (2.1) leads to a fixed point, but that the other three conditions do not guarantee a fixed point.

THEOREM 1. Suppose $\mathrm{X}$ is a d-complete Hausdorff topological space, $\mathrm{C}$ is a closed subset of $\mathrm{X}$, and $\mathrm{T}: \mathrm{C} \rightarrow \mathrm{X}$ is an open mapping with $\mathrm{C} \subset \mathrm{T}(\mathrm{C})$ which satisfies $\mathrm{d}(\mathrm{x}, \mathrm{y}) \leq k(\mathrm{~d}(\mathrm{~T} x, \mathrm{Ty}))$ for all $\mathrm{x}, \mathrm{y} \in \mathrm{C}$ where $k:[0, \infty) \rightarrow[0, \infty), k(0)=0$, and $k$ is non-decreasing. Then $\mathrm{T}$ has a fixed point if and only if there exists $\mathrm{x}_{0} \in \mathrm{C}$ with $\sum_{n=1}^{\infty} k^{n}\left(\mathrm{~d}\left(\mathrm{Tx}_{0}, \mathrm{x}_{0}\right)\right)<\infty$.

PROOF. Notice that the condition $\mathrm{d}(\mathrm{x}, \mathrm{y}) \leq k(\mathrm{~d}(\mathrm{~T} x, \mathrm{Ty}))$ forces $\mathrm{T}$ to be one-to-one. Hence $\mathrm{T}^{-1}$ exists. Also, $\mathrm{T}$ is open implies that $\mathrm{T}^{-1}$ is continuous, and thus $\omega$-continuous.

If $\mathrm{p}=\mathrm{Tp}$ then $\sum_{n=1}^{\infty} k^{n}(\mathrm{~d}(\mathrm{~T} \mathrm{p}, \mathrm{p}))=0<\infty$

Suppose there exists $\mathrm{x}_{0} \in \mathrm{C}$ such that $\sum_{n=1}^{\infty} k^{n}\left(\mathrm{~d}\left(\mathrm{Tx}_{0}, \mathrm{x}_{0}\right)\right)<\infty$. We know that $\mathrm{T}^{-1}$ exists, so let $\mathrm{T}_{1}$ be $\mathrm{T}^{-1}$ restricted to $\mathrm{C}$. Then $\mathrm{T}_{1}: \mathrm{C} \rightarrow \mathrm{C}$ and $\mathrm{d}\left(\mathrm{T}_{1} \mathrm{x}, \mathrm{T}_{1} \mathrm{y}\right) \leq k(\mathrm{~d}(\mathrm{x}, \mathrm{y}))$ for all $\mathrm{x}$, $\mathrm{y} \in \mathrm{C}$. Let $\mathrm{y}=\mathrm{T}_{1} \mathrm{x}$. Then $\mathrm{d}\left(\mathrm{T}_{1} \mathrm{x}, \mathrm{T}_{1}^{2} \mathrm{x}\right) \leq k\left(\mathrm{~d}\left(\mathrm{x}, \mathrm{T}_{1} \mathrm{x}\right)\right)$ for all $\mathrm{x} \in \mathrm{C}$. In particular, $\mathrm{d}\left(\mathrm{T}_{1} \mathrm{x}_{0}, \mathrm{~T}_{1}^{2} \mathrm{x}_{0}\right) \leq k\left(\mathrm{~d}\left(\mathrm{x}_{0}, \mathrm{~T}_{1} \mathrm{x}_{0}\right)\right) \leq k^{2}\left(\mathrm{~d}\left(\mathrm{Tx}_{0}, \mathrm{x}_{0}\right)\right)$. By induction, $\mathrm{d}\left(\mathrm{T}_{1}^{n-1} \mathrm{x}_{0}, \mathrm{~T}_{1}^{n} \mathrm{x}_{0}\right) \leq k^{n}\left(\mathrm{~d}\left(\mathrm{Tx}_{0}, \mathrm{x}_{0}\right)\right)$. Thus,

$$
\sum_{k=1}^{\infty} \mathrm{d}\left(\mathrm{T}_{1}^{n-1} \mathrm{x}_{0}, \mathrm{~T}_{1}^{n} \mathrm{x}_{0}\right) \leq \sum_{k=1}^{\infty} k^{n}\left(\mathrm{~d}\left(\mathrm{~T} \mathrm{x}_{0}, \mathrm{x}_{0}\right)\right)<\infty
$$

Since $\mathrm{X}$ is $\mathrm{d}$-complete, $\mathrm{T}_{1}^{n} \mathrm{x}_{0}$ converges, say to $\mathrm{p}$. Note that $\mathrm{p}$ is in $\mathrm{C}$ since $\mathrm{C}$ is closed. Now $T_{1}\left(T_{1}^{n} x_{0}\right) \rightarrow T_{1} p$ as $n \rightarrow \infty$ since $T_{1}$ is $\omega$-continuous. But $T_{1}^{n+1} x_{0} \rightarrow p$ as $n \rightarrow \infty$, and since limits are unique in $X, T_{1} p=p$. Now $T\left(T_{1} p\right)=T(p)$ and $T\left(T_{1} p\right)=p$ so $T p=p$ and $T$ has a fixed point.

COROLLARY 1. Suppose $\mathrm{T}: \mathrm{C} \rightarrow \mathrm{X}$ where $\mathrm{C}$ is a closed subset of a d-complete Hausdorff symmetrizable topological space with $\mathrm{C} \subset \mathrm{T}(\mathrm{C})$. Suppose $\mathrm{d}(\mathrm{x}, \mathrm{y}) \leq[\mathrm{d}(\mathrm{Tx}, \mathrm{Ty})]^{p}$ where $\mathrm{p}>1$ for all $x, y \in C$. If there exists $x_{0} \in C$ such that $d\left(\operatorname{Tx}_{0}, x_{0}\right)<1$, then $T$ has a fixed point.

PROOF. If $\mathrm{x} \neq \mathrm{y}, 0<\mathrm{d}(\mathrm{x}, \mathrm{y}) \leq[\mathrm{d}(\mathrm{Tx}, \mathrm{Ty})]^{p}$ and $\mathrm{T} \mathrm{x} \neq \mathrm{Ty}$. Thus $\mathrm{T}$ is one-to-one and $\mathrm{T}^{-1}$ exists. Now $\mathrm{d}\left(\mathrm{T}^{-1} \mathrm{x}, \mathrm{T}^{-1} \mathrm{y}\right) \leq[\mathrm{d}(\mathrm{x}, \mathrm{y})]^{p}$ implies that $\mathrm{T}^{-1}$ is continuous. Hence $\mathrm{T}$ must be 
open. Let $x_{0}$ be a point in $C$ such that $\left.d\left(T x_{0}\right) \cdot x_{0}\right)<1$. If $d\left(T x_{0}, x_{0}\right)=0$. then $x_{0}$ is a fixed point of $T$. Suppose $0<d\left(T x_{0}\right.$. $\left.x_{0}\right)<1$. Let $k(t)=t^{\prime \prime}$. and $\left.t=d\left(T x_{0}\right) \cdot x_{0}\right)$. Note that $(n t)^{\prime \prime}<\alpha t^{p}$ if $0<a<1$. Since $t^{p}<\mathrm{t}$. these is an $a_{1} \in(0.1)$ such that $\mathrm{t}^{\prime}=\alpha_{1} \mathrm{t}^{\mathrm{s}}$. Now $\left(\mathrm{t}^{\prime}\right)^{\prime \prime}<\mathrm{t}^{\prime \prime}$ and there is an $\alpha_{2} \in(0.1)$ such that $\mathrm{t}^{2 p}=0_{2} \mathrm{t}^{\prime}$. But $\alpha_{2} \mathrm{t}^{\prime \prime}=\mathrm{t}^{2 p}=\left(\mathrm{t}^{p}\right)^{p}=\left(\alpha_{1} \mathrm{t}^{p}<\alpha_{1} \mathrm{t}^{\prime}\right.$. Hence $\alpha_{2}<\alpha_{1}$.

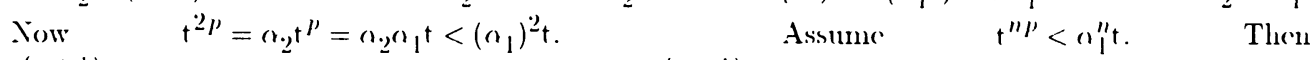

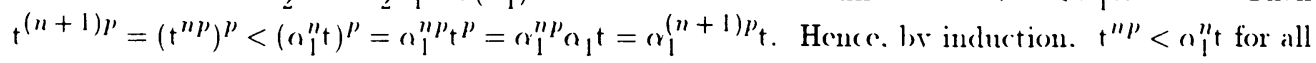
notural numbers n. Therefore.

$$
\sum_{n=1}^{\infty} k^{n}\left(\mathrm{~d}\left(\mathrm{~T}_{\mathrm{x}_{0}} \cdot \mathrm{x}_{0}\right)\right)=\sum_{n=1}^{\infty}\left[\mathrm{d}\left(\mathrm{Tx}_{0}, \mathrm{x}_{0}\right)\right]^{n p}=\sum_{n=1}^{\infty} \mathrm{t}^{n p}<\sum_{n=1}^{\infty} \mathrm{o}_{1}^{n} \mathrm{t}<\infty
$$

since $0<\alpha_{1}<1$. Applying Theorem 1, we get that $\mathrm{T}$ has a fixed point.

If $\mathrm{T}$ is not open one could check the following condition.

THEOREM 2. Let $\mathrm{X}$ be a d-complete Hausdorff topological space, $\mathrm{C}$ be a closed subset of $\mathrm{X}, \mathrm{T}: \mathrm{C} \rightarrow \mathrm{X}$ with $\mathrm{C} \subset \mathrm{T}(\mathrm{C})$. Suppose there exists $k:[0, \infty) \rightarrow[0, \infty)$ such that $\mathrm{k}(\mathrm{d}(\mathrm{Tx}, \mathrm{Ty})) \geq \mathrm{d}(\mathrm{x}, \mathrm{y})$ for all $\mathrm{x}, \mathrm{y} \in \mathrm{C}, k$ is non-decreasing, $k(0)=0$, and there exists $\mathrm{x}_{0} \in \mathrm{C}$ such that $\sum_{n=1}^{\infty} k^{n}\left(\mathrm{~d}\left(\mathrm{Tx}_{0}, \mathrm{x}_{0}\right)\right)<\infty$. If $\mathrm{G}(\mathrm{x})=\mathrm{d}(\mathrm{Tx}, \mathrm{x})$ is lower semi-continuous on $\mathrm{C}$ then $\mathrm{T}$ has a fixed point.

PROOF. If $\mathrm{x} \neq \mathrm{y}, 0<\mathrm{d}(\mathrm{x}, \mathrm{y}) \leq k(\mathrm{~d}(\mathrm{Tx}, \mathrm{Ty}))$ so that $\mathrm{d}(\mathrm{Tx}, \mathrm{Ty}) \neq 0$. Hence $\mathrm{T}$ is one-to-one and $\mathrm{T}^{-1}$ exists. Let $\mathrm{T}_{1}$ be $\mathrm{T}^{-1}$ restricted to $\mathrm{C}$. Now $\mathrm{T}_{1}: \mathrm{C} \rightarrow \mathrm{C}$ and for $\mathrm{x} \in \mathrm{C}$, $\mathrm{d}\left(\mathrm{x}, \mathrm{T}_{1} \mathrm{x}\right) \leq k(\mathrm{~d}(\mathrm{~T} \mathrm{x}, \mathrm{x})), \mathrm{d}\left(\mathrm{T}_{1} \mathrm{x}, \mathrm{T}_{1}^{2} \mathrm{x},\right) \leq k\left(\mathrm{~d}\left(\mathrm{x}, \mathrm{T}_{1} \mathrm{x}\right)\right) \leq k^{2}(\mathrm{~d}(\mathrm{~T} \mathrm{x}, \mathrm{x}))$. By induction, $\mathrm{d}\left(\mathrm{T}_{1}^{n-1} \mathrm{x}, \mathrm{T}_{1}^{n} \mathrm{x}\right) \leq k^{n}(\mathrm{~d}(\mathrm{Tx}, \mathrm{x}))$. There exists $\mathrm{x}_{0} \in \mathrm{C}$ with $\sum_{n=1}^{\infty} k^{n}\left(\mathrm{~d}\left(\mathrm{Tx}_{0}, \mathrm{x}_{0}\right)\right)<\infty$ implies $\sum_{n=1}^{\infty} \mathrm{d}\left(\mathrm{T}_{1}^{n-1} \mathrm{x}_{0}, \mathrm{~T}_{1}^{n} \mathrm{x}_{0}\right)<\infty$. Sincc $\mathrm{X}$ is d-complete there exists $\mathrm{p} \in \mathrm{X}$ such that $\mathrm{T}_{1}^{n} \mathrm{x}_{0} \rightarrow \mathrm{p}$ as $\mathrm{n} \rightarrow \infty$. Note that $\mathrm{p} \in \mathrm{C}$ since $\mathrm{T}_{1}^{n} \mathrm{x}_{0} \in \mathrm{C}$ for all $\mathrm{n}$ and $\mathrm{C}$ is closed. Now $\mathrm{G}(\mathrm{x})=\mathrm{d}(\mathrm{T} x, \mathrm{x})$ is lower semi-continuous on $C$ gives $G(p) \leq \lim \inf G\left(T_{1}^{n} x_{0}\right)$ or $d(T p, p) \leq \lim \inf d\left(T_{1}^{n-1} x_{0}, T_{1}^{n} x_{0},\right)=0$. Thus $\mathrm{T}_{\mathrm{p}}=\mathrm{p}$.

In [5], Hicks gives several examples of functions $k$ which satisfy the condition of theorem 1 of that paper. These examples, with a slight modification, carry over to the non-self map case. The non-self map version of Example 1 is given for completeness. The other examples carry over in a similar manner.

EXAMPLE 1. Suppose $0<\lambda<1$. Let $k(\mathrm{t})=\lambda \mathrm{t}$ for $\mathrm{t} \geq 0$. If $\mathrm{d}(\mathrm{x}, \mathrm{y}) \leq \lambda \mathrm{d}(\mathrm{Tx}, \mathrm{Ty}), \mathrm{T}$ is open since $\mathrm{T}^{-1}$ exists and is continuous. Let $\mathrm{x} \in \mathrm{C}$. There exists $\mathrm{y} \in \mathrm{C}$ such that $\mathrm{T} y=x$. Now $\mathrm{d}(\mathrm{x}, \mathrm{y})=\mathrm{d}(\mathrm{Ty}, \mathrm{y}) \leq \lambda \mathrm{d}\left(\mathrm{T}^{2} \mathrm{y}, \mathrm{Ty}\right) \quad$ and $\quad \sum_{n=1}^{\infty} k^{n}(\mathrm{~d}(\mathrm{~T} y, \mathrm{y})) \leq \sum_{n=1}^{\infty} \lambda^{n} \mathrm{~d}\left(\mathrm{~T}^{2} \mathrm{y}, \mathrm{Ty}\right)<\infty$. Applying Theorem 1 we get a fixed point for T. (Note: $d(x, y) \leq \lambda d(T x$, Ty) for $0<\lambda<1$ is equivalent to $\mathrm{d}(\mathrm{T} x, \mathrm{Ty}) \geq \alpha \mathrm{d}(\mathrm{x}, \mathrm{y})$ for $\alpha>1$.)

The following examples show that conditions (2.2), (2.3) and (2.4) do not guarantee fixed points.

EXAMPLE 2. Let $\mathbb{R}$ denote the real numbers and $\mathrm{CB}(\mathbb{R}, \mathbb{R})$ denote the collection of all bounded and continuous functions which map $\mathbb{R}$ into $\mathbb{R}$. Let

$$
C=\left\{f \in C B(\mathbb{R}, \mathbb{R}): f(t)=0 \text { for all } t \leq 0 \text { and } \lim _{t \rightarrow \infty} f(t) \geq 1\right\}
$$


Define $\mathrm{T}: \mathrm{C} \rightarrow \mathrm{CB}(\mathbb{R}, \mathbb{R})$ by $\mathrm{Tf}(\mathrm{t})=\frac{1}{2} \mathrm{f}(\mathrm{t}+1)$ and let $k(\mathrm{t})=\frac{\mathrm{t}}{3}$. Then $\mathrm{d}(\mathrm{Tf}, \mathrm{Tg})=\frac{1}{2} \mathrm{~d}(\mathrm{f}, \mathrm{g}) \geq k(\mathrm{~d}(\mathrm{f}, \mathrm{g}))$. $k$ satisfies condition (2.2) but, as shown in [6], $\mathrm{T}$ docs not have a fixed point.

EXAMPLE 3. Let $\mathrm{T}:[1, \infty) \rightarrow[0, \infty)$ be defined by $\mathrm{T} x=\mathrm{x}-\frac{1}{\mathrm{x}}$ and let $h(\mathrm{t})=\frac{\mathrm{t}}{2}$. Then $\mathrm{d}(\mathrm{Tx}, \mathrm{Ty}) \leq 2 \mathrm{~d}(\mathrm{x}, \mathrm{y})$ or $\mathrm{d}(\mathrm{x}, \mathrm{y}) \geq k(\mathrm{~d}(\mathrm{Tx}, \mathrm{Ty})) . k$ satisfies condition $(2.3)$ but $\mathrm{T}$ does not have a fixed point.

EXAMPLE 4. Let $c_{0}$ denote the collection of all sequences that converge to zero. Let $\mathrm{C}=\left\{\mathrm{x} \in \mathrm{c}_{0}:\|\mathrm{x}\|=1\right.$ and $\left.\mathrm{x}_{0}=1\right\}$. Define $\mathrm{T}: \mathrm{C} \rightarrow \mathrm{c}_{0}$ by $\mathrm{Tx}=\mathrm{y}$ where $\mathrm{y}_{n}=\mathrm{x}_{n+1}, \mathrm{n}=0,1,2, \ldots$, and let $k(\mathrm{t})=2 \mathrm{t}$. Then $\mathrm{d}(\mathrm{Tx}, \mathrm{Ty})=\mathrm{d}(\mathrm{x}, \mathrm{y}) \leq 2 \mathrm{~d}(\mathrm{x}, \mathrm{y})=k(\mathrm{~d}(\mathrm{x}, \mathrm{y}))$ for all $\mathrm{x}, \mathrm{y} \in \mathrm{C}$. $k$ satisfies condition (2.4) but, as shown in [6], $\mathrm{T}$ does not have a fixed point.

The following theorems were motivated by the work of Hicks and Rhoades [3].

THEOREM 3. Let $\mathrm{C}$ be a compact subset of a Hausdorff topological space $(\mathrm{X}, \mathrm{t})$ and $d: X \times X \rightarrow[0, \infty)$ such that $d(x, y)=0$ if and only if $x=y$. Suppose $T: C \rightarrow X$ with $C \subset T(C)$, $T$ and $G(x)=d(x, T x)$ are both continuous, and $d\left(T x, T^{2} x\right)>d(x, T x)$ for all $x \in T^{-1}(C)$ with $\mathrm{x} \neq \mathrm{T} x$. Then $\mathrm{T}$ has a fixed point in $\mathrm{C}$.

PROOF. $\mathrm{C}$ is a compact subset of a Hausdorff space so it is closed. $\mathrm{T}$ is continuous so $T^{-1}(C)$ is closed and hence is compact since $T^{-1}(C) \subset C . G(x)$ is continuous so it attains its minimum on $T^{-1}(C)$, say at $z$. Now $z \in C \subset T(C)$ so there exists $y \in T^{-1}(C)$ such that $T y=z$. If $y \neq z$ then $d(z, T z)=d\left(T y, T^{2} y\right)>d(y, T y)$, a contradiction. Thus $y=z=T y$ is a fixed point of $\mathrm{T}$.

THEOREM 4. Let $\mathrm{C}$ be a compact subset of a Hausdorff topological space $(\mathrm{X}, \mathrm{t})$ and $d: X \times X \rightarrow[0, \infty)$ such that $d(x, y)=0$ if and only if $x=y$. Suppose $T: C \rightarrow X$ with $C \subset T(C)$, $T$ and $G(x)=d(x, T x)$ are both continuous, $f:[0, \infty) \rightarrow[0, \infty)$ is continuous and $f(t)>0$ for $\mathrm{t} \neq 0$. If we know that $d\left(\mathrm{Tx}, \mathrm{T}^{2} \mathrm{x}\right) \leq \lambda \mathrm{f}(\mathrm{d}(\mathrm{x}, \mathrm{Tx}))$ for all $\mathrm{x} \in \mathrm{T}^{-1}(\mathrm{C})$ implies $\mathrm{T}$ has a fixed point where $0<\lambda<1$, then $d\left(T x, T^{2} x\right)<f(d(x, T x))$ for all $x \in T^{-1}(C)$ such that $f(d(x, T x)) \neq 0$ gives a fixed point.

PROOF. $\mathrm{C}$ is a compact subset of a Hausdorff space so it is closed. $\mathrm{T}$ is continuous gives that $T^{-1}(C)$ is closed, and $T^{-1}(C) \subset C$ so $T^{-1}(C)$ is compact. Suppose $x \neq T x$ for all $x \in T^{-1}(C)$. Then $d(x, T x)>0$ so that $f(d(x, T x))>0$ for all $x \in T^{-1}(C)$. Define $P(x)$ on $T^{-1}(C)$ by $P(x)=\frac{d\left(T x T^{2} x\right)}{f(d(x, T x))}$. $P$ is continuous since $T, f$ and $G(x)$ are continuous. Therefore $P$ attains its maximum on $T^{-1}(C)$, say at $z . P(x) \leq P(z)<1$ so $d\left(T x, T^{2} x\right) \leq P(z) f(d(x, T x))$ and $\mathrm{T}$ must have a fixed point.

THEOREM 5. Let $C$ be a compact subset of a Hausdorff topological space $(X, t)$ and $d: X \times X \rightarrow[0, \infty)$ such that $d(x, y)=0$ if and only if $x=y$. Suppose $T: C \rightarrow X$ with $C \subset T(C)$, $T$ and $G(x)=d(x, T x)$ are both continuous, $f:[0, \infty) \rightarrow[0, \infty)$ is continuous and $f(t)>0$ for $t \neq 0$. If we know that $d\left(T x, T^{2} x\right) \geq \lambda f(d(x, T x))$ for all $x \in T^{-1}(C)$ implies $T$ has a fixed point where $\lambda>1$, then $d\left(T x, T^{2} x\right)>f(d(x, T x))$ for all $x \in T^{-1}(C)$ such that $f(d(x, T x)) \neq 0$ gives a fixed point. 
PROOF. $\mathrm{C}$ is a compact subset of a Hausdorff space so it is closed. $\mathrm{T}$ is continuous gives that $T^{-1}(C)$ is closed and hence compact, since $T^{-1}(C) \subset C$. Suppose $x \neq T x$ for all $x \in T^{-1}(C)$. Then $d(x, T x)>0$ and $f(d(x, T x))>0$. Define $P(x)=\frac{d\left(T x, T^{2} x\right)}{f(d(x)}$. P is continuous since $T, f$ and $G$ are continuous. $P$ attains it minimum on $T^{-1}(C)$, say at $\% P(x) \geq P(\%)>1$ so $d\left(T x, T^{2} x\right) \geq P(\%) f(d(x, T x))$ and $T$ must have a fixed point.

Theorems 6, 7 and 8 are generalizations of theorems by Kang [ 7$]$. The following family of real functions was originally introduced by M. A. Khan, M. S. Khan, and S. Sessa in [8]. Let $\Phi$ denote the family of all real functions $\phi:\left(\mathbb{R}^{+}\right)^{3} \rightarrow \mathbb{R}^{+}$satisfying the following conditions:

$\left(C_{1}\right) \phi$ is lower-semicontinuous in each coordinate variable,

$\left(\mathrm{C}_{2}\right)$ Let $\mathrm{v}, \mathrm{w} \in \mathbb{R}^{+}$be such that either $\mathrm{v} \geq \phi(\mathrm{v}, \mathrm{w}, \mathrm{w})$ or $\mathrm{v} \geq \phi(\mathrm{w}, \mathrm{v}, \mathrm{w})$. Then $\mathrm{v} \geq \mathrm{hw}$, where $\phi(1,1,1)=\mathrm{h}>1$.

THEOREM 6. Let $(\mathrm{X}, \mathrm{t}, \mathrm{d})$ be a d-complete topological space where $\mathrm{d}$ is a continuous symmetric. Let $A$ and $B$ map $C$, a closed subset of $X$, into (onto) $X$ such that $C \subset A(C)$, $C \subset B(C)$, and $d(A x, B y) \geq \phi(d(A x, x), d(B y, y), d(x, y))$ for all $x, y$ in $C$ where $\phi \in \Phi$. Then $A$ and $\mathrm{B}$ have a common fixed point in $\mathrm{C}$.

PROOF. Fix $x_{0} \in C$. Since $C \subset A(C)$ there exists $x_{1} \in C$ such that $A x_{1}=x_{0}$. Now $\mathrm{C} \subset \mathrm{B}(\mathrm{C})$ so there exists $\mathrm{x}_{2} \in \mathrm{C}$ such that $\mathrm{Bx}_{2}=\mathrm{x}_{1}$. Build the sequence $\left\{\mathrm{x}_{n}\right\}_{n=0}^{\infty}$ by $\mathrm{Ax}_{2 n+1}=\mathrm{x}_{2 n}, \mathrm{Bx}_{2 n+2}=\mathrm{x}_{2 n+1}$. Now if $\mathrm{x}_{2 n+1}=\mathrm{x}_{2 n}$ for some $\mathrm{n}$, the $\mathrm{x}_{2 n+1}$ is a fixed point of A. Then

$$
\begin{aligned}
\mathrm{d}\left(\mathrm{x}_{2 n+1}, \mathrm{x}_{2 n+1}\right) & =\mathrm{d}\left(\mathrm{x}_{2 n}, \mathrm{x}_{2 n+1}\right) \\
& =\mathrm{d}\left(\mathrm{Ax}_{2 n+1}, \mathrm{Bx}_{2 n+2}\right) \\
& \geq \phi\left(\mathrm{d}\left(\mathrm{Ax}_{2 n+1}, \mathrm{x}_{2 n+1}\right), \mathrm{d}\left(\mathrm{Bx}_{2 n+2}, \mathrm{x}_{2 n+2}\right), \mathrm{d}\left(\mathrm{x}_{2 n+1}, \mathrm{x}_{2 n+2}\right)\right) \\
& =\phi\left(0, \mathrm{~d}\left(\mathrm{x}_{2 n+1}, \mathrm{x}_{2 n+2}\right), \mathrm{d}\left(\mathrm{x}_{2 n+1}, \mathrm{x}_{2 n+2}\right)\right)
\end{aligned}
$$

By property $\left(\mathrm{C}_{2}\right), \mathrm{d}\left(\mathrm{x}_{2 n}, \mathrm{x}_{2 n+1}\right) \geq \mathrm{hd}\left(\mathrm{x}_{2 n+1}, \quad \mathrm{x}_{2 n+2}\right)$. Hence, $\mathrm{x}_{2 n+1}=\mathrm{x}_{2 n+2}$ and $\mathrm{Bx}_{2 n+1}=\mathrm{Bx}_{2 n+2}=\mathrm{x}_{2 n+1}$. Therefore $\mathrm{x}_{2 n+1}$ is a common fixed point of $\mathrm{A}$ and $\mathrm{B}$. Now if $\mathrm{x}_{2 n+1}=\mathrm{x}_{2 n+2}$ for some $\mathrm{n}$, then $\mathrm{Bx}_{2 n+2}=\mathrm{Bx}_{2 n+1}=\mathrm{x}_{2 n+2}$. Then

$$
\begin{aligned}
\mathrm{d}\left(\mathrm{x}_{2 n+2}, \mathrm{x}_{2 n+1}\right) & =\mathrm{d}\left(\mathrm{Ax}_{2 n+3}, \mathrm{Bx}_{2 n+2}\right) \\
& \geq \phi\left(\mathrm{d}\left(\mathrm{Ax}_{2 n+3}, \mathrm{x}_{2 n+3}\right), \mathrm{d}\left(\mathrm{Bx}_{2 n+2}, \mathrm{x}_{2 n+2}\right), \mathrm{d}\left(\mathrm{x}_{2 n+3}, \mathrm{x}_{2 n+2}\right)\right) \\
& =\phi\left(\mathrm{d}\left(\mathrm{x}_{2 n+2}, \mathrm{x}_{2 n+3}\right), \mathrm{d}\left(\mathrm{x}_{2 n+1}, \mathrm{x}_{2 n+2}\right), \mathrm{d}\left(\mathrm{x}_{2 n+3}, \mathrm{x}_{2 n+2}\right)\right) .
\end{aligned}
$$

By property $\left(\mathrm{C}_{2}\right), \mathrm{d}\left(\mathrm{x}_{2 n+1}, \quad \mathrm{x}_{2 n+2}\right) \geq \mathrm{hd}\left(\mathrm{x}_{2 n+2}, \quad \mathrm{x}_{2 n+3}\right)$ or $\mathrm{x}_{2 n+2}=\mathrm{x}_{2 n+3}$. Thus $\mathrm{Ax}_{2 n+2}=\mathrm{Ax}_{2 n+3}=\mathrm{x}_{2 n+2}$ and $\mathrm{x}_{2 n+2}$ is a fixed point of $\mathrm{A}$ also.

Suppose $x_{n} \neq x_{n+1}$ for all $n$. Then

$$
\begin{aligned}
\mathrm{d}\left(\mathrm{x}_{2 n}, \mathrm{x}_{2 n+1}\right) & =\mathrm{d}\left(\mathrm{Ax}_{2 n+1}, \mathrm{Bx}_{2 n+2}\right) \\
& \geq \phi\left(\mathrm{d}\left(\mathrm{Ax}_{2 n+1}, \mathrm{x}_{2 n+1}\right), \mathrm{d}\left(\mathrm{Bx}_{2 n+2}, \mathrm{x}_{2 n+2}\right), \mathrm{d}\left(\mathrm{x}_{2 n+1}, \mathrm{x}_{2 n+2}\right)\right) \\
& =\phi\left(\mathrm{d}\left(\mathrm{x}_{2 n}, \mathrm{x}_{2 n+1}\right), \mathrm{d}\left(\mathrm{x}_{2 n+1}, \mathrm{x}_{2 n+2}\right), \mathrm{d}\left(\mathrm{x}_{2 n+1}, \mathrm{x}_{2 n+2}\right)\right) .
\end{aligned}
$$


Again by $\left(\mathrm{C}_{2}\right), \mathrm{d}\left(\mathrm{x}_{2 n}, \mathrm{x}_{2 n+1}\right) \geq \mathrm{hd}\left(\mathrm{x}_{2 n+1}, \mathrm{x}_{2 n+2}\right)$ or $\mathrm{d}\left(\mathrm{x}_{2 n+1}, \mathrm{x}_{2 n+2}\right) \leq \frac{1}{h} \mathrm{~d}\left(\mathrm{x}_{2 n}, \mathrm{x}_{2 n+1}\right)$. Also,

$$
\begin{aligned}
\mathrm{d}\left(\mathrm{x}_{2 n+1}, \mathrm{x}_{2 n+2}\right) & =\mathrm{d}\left(\mathrm{Ax}_{2 n+3}, \mathrm{Bx}_{2 n+2}\right) \\
& \geq \phi\left(\mathrm{d}\left(\mathrm{Ax}_{2 n+3}, \mathrm{x}_{2 n+3}\right), \mathrm{d}\left(\mathrm{Bx}_{2 n+2}, \mathrm{x}_{2 n+2}\right), \mathrm{d}\left(\mathrm{x}_{2 n+3}, \mathrm{x}_{2 n+2}\right)\right) \\
& =\phi\left(\mathrm{d}\left(\mathrm{x}_{2 n+2}, \mathrm{x}_{2 n+3}\right), \mathrm{d}\left(\mathrm{x}_{2 n+1}, \mathrm{x}_{2 n+2}\right), \mathrm{d}\left(\mathrm{x}_{2 n+3}, \mathrm{x}_{2 n+2}\right)\right)
\end{aligned}
$$

By $\left(\mathrm{C}_{2}\right)$ we get $\mathrm{d}\left(\mathrm{x}_{2 n+2}, \mathrm{x}_{2 n+3}\right) \leq \frac{1}{\mathrm{~h}} \mathrm{~d}\left(\mathrm{x}_{2 n+1}, \mathrm{x}_{2 n+2}\right)$. Induction gives

$\mathrm{d}\left(\mathrm{x}_{n+1}, \mathrm{x}_{n+2}\right) \leq\left(\frac{1}{\mathrm{~h}}\right)^{n+1} \mathrm{~d}\left(\mathrm{x}_{0}, \mathrm{x}_{1}\right)$. Thus $\sum_{n=1}^{\infty} \mathrm{d}\left(\mathrm{x}_{n+1}, \mathrm{x}_{n+2}\right) \leq \sum_{n=1}^{\infty}\left(\frac{1}{\mathrm{~h}}\right)^{n+1} \mathrm{~d}\left(\mathrm{x}_{0}, \mathrm{x}_{1}\right)<\infty$. X

is $d$-complete so $x_{n} \rightarrow p$ as $n \rightarrow \infty$ where $p \in C$, since $C$ is closed. We also have $x_{2 n} \rightarrow p$ and $\mathrm{x}_{2 n+1} \rightarrow \mathrm{p}$ as $\mathrm{n} \rightarrow \infty$. This gives $\mathrm{Ax}_{2 n+1} \rightarrow \mathrm{p}$ and $\mathrm{Bx}_{2 n+2} \rightarrow \mathrm{p}$ as $\mathrm{n} \rightarrow \infty$. Since $\mathrm{p} \in \mathrm{C}$, $p \in A(C)$ and $p \in B(C)$, so there exist $v, w \in C$ such that $A v=p$ and $B w=p$. Now

$$
\begin{aligned}
\mathrm{d}\left(\mathrm{x}_{2 n}, \mathrm{p}\right) & =\mathrm{d}\left(\mathrm{Ax}_{2 n+1}, \mathrm{Bw}\right) \\
& \geq \phi\left(\mathrm{d}\left(\mathrm{Ax}_{2 n+1}, \mathrm{x}_{2 n+1}\right), \mathrm{d}(\mathrm{Bw}, \mathrm{w}), \mathrm{d}\left(\mathrm{x}_{2 n+1}, \mathrm{w}\right)\right) .
\end{aligned}
$$

Since $\phi$ is lower-semicontinuous, letting $n \rightarrow \infty$ gives $d(p, p) \geq \phi(0, d(p, w), d(p, w))$ and by $\left(C_{2}\right)$ we have $0 \geq \mathrm{h} \mathrm{d}(\mathrm{p}, \mathrm{w})$. Hence $\mathrm{p}=\mathrm{w}$. Also, $\mathrm{d}\left(\mathrm{p}, \mathrm{x}_{2 n+1}\right)=\mathrm{d}\left(\mathrm{Av}, \mathrm{Bx}_{2 n+1}\right) \geq \phi\left(\mathrm{d}(\mathrm{Av}, \mathrm{v}), \mathrm{d}\left(\mathrm{Bx}_{2 n+2}, \mathrm{x}_{2 n+2}\right), \mathrm{d}\left(\mathrm{v}, \mathrm{x}_{2 n+1}\right)\right)$.

Letting $\mathrm{n} \rightarrow \infty$ gives $\mathrm{d}(\mathrm{p}, \mathrm{p}) \geq \phi(\mathrm{d}(\mathrm{p}, \mathrm{v}), 0, \mathrm{~d}(\mathrm{v}, \mathrm{p}))$ or, by $\left(\mathrm{C}_{2}\right), 0 \geq \mathrm{hd}(\mathrm{p}, \mathrm{v})$. Hence $\mathrm{p}=\mathrm{v}$. Therefore, $A p=A v=p=B w=B p$.

COROLlARY 2. Let $\mathrm{A}$ and $\mathrm{B}$ map $\mathrm{C}$, a closed subset of $\mathrm{X}$, into (onto) $\mathrm{X}$ such that $\mathrm{C} \subset \mathrm{A}(\mathrm{C}), \mathrm{C} \subset \mathrm{B}(\mathrm{C})$, and $\mathrm{d}(\mathrm{Ax}, \mathrm{By}) \geq a \mathrm{~d}(\mathrm{Ax}, \mathrm{x})+b \mathrm{~d}(\mathrm{By}, \mathrm{y})+c \mathrm{~d}(\mathrm{x}, \mathrm{y})$ for all $\mathrm{x}, \mathrm{y} \in \mathrm{C}$, where $a, b$, and $c$ are non-negative real numbers with $a<1, b<1$, and $a+b+c>1$. Then $\mathrm{A}$ and $\mathrm{B}$ have a common fixed point in $\mathrm{C}$.

The proof of Corollary 2 is identical to the proof of Corollary 2.3 in [9].

In [7], Kang defined $\Phi^{*}$ to be the family of all real functions $\varphi \rightarrow\left(\mathbb{R}^{+}\right)^{3} \rightarrow \mathbb{R}^{+}$satisfying condition $\left(\mathrm{C}_{1}\right)$ and the following condition:

$\left(\mathrm{C}_{3}\right)$ Let $\mathrm{v}, \mathrm{w} \in \mathbf{R}^{+}-\{0\}$ be such that either $\mathrm{v} \geq \varphi(\mathrm{v}, \mathrm{w}, \mathrm{w})$ or $\mathbf{v} \geq \varphi(\mathrm{w}, \mathrm{v}, \mathrm{w})$. Then $\mathrm{v} \geq \mathrm{hw}$, where $\varphi(1,1,1)=\mathrm{h}>1$. Kang showed that the family $\Phi^{*}$ is strictly larger than the family $\Phi$.

THEOREM 7. Let $(X, t, d)$ be a d-complete Hausdorff topological space where $d$ is a continuous symmetric. If $\mathrm{A}$ and $\mathrm{B}$ are continuous mappings from $\mathrm{C}$, a closed subset of $\mathrm{X}$, into $\mathrm{X}$ such that $\mathrm{C} \subset \mathrm{A}(\mathrm{C}), \mathrm{C} \subset \mathrm{B}(\mathrm{C})$, and $\mathrm{d}(\mathrm{Ax}, \mathrm{By}) \geq \varphi(\mathrm{d}(\mathrm{Ax}, \mathrm{x}), \mathrm{d}(\mathrm{By}, \mathrm{y}), \mathrm{d}(\mathrm{x}, \mathrm{y}))$ for all $\mathrm{x}, \mathrm{y} \in \mathrm{C}$ such that $\mathrm{x} \neq \mathrm{y}$ where $\varphi \in \Phi^{*}$, then $\mathrm{A}$ or $\mathrm{B}$ has a fixed point or $\mathrm{A}$ and $\mathrm{B}$ have a common fixed point.

PROOF. Let $\left\{x_{n}\right\}_{n=0}^{\infty}$ be defined as in the proof of Theorem 6. If $x_{n}=x_{n+1}$ for some $n$ then $A$ or $B$ has a fixed point. Suppose $x_{n} \neq x_{n+1}$ for all $n$. As in the proof of Theorem 6, $\mathrm{x}_{n} \rightarrow \mathrm{p}$ as $\mathrm{n} \rightarrow \infty$. Now $\left\{\mathrm{x}_{2 n}\right\}_{n=0}^{\infty}$ and $\left\{\mathrm{x}_{2 n+1}\right\}_{n=0}^{\infty}$ are subsequences of $\left\{\mathrm{x}_{n}\right\}_{n=1}^{\infty}$ and hence each converges to $p$. Since $A$ and $B$ are continuous, $A x_{2 n+1}=x_{2 n} \rightarrow A p$ and $\mathrm{Bx}_{2 n+2}=\mathrm{x}_{2 n+1} \rightarrow \mathrm{Bp}$. Limits in $\mathrm{X}$ are unique, because $\mathrm{X}$ is Hausdorff, so $\mathrm{Ap}=\mathrm{p}=\mathrm{Bp}$. 
COROLLARY 3. Let $A$ and $B$ be continuous mappings from $C$, a closed subset of $X$, into $X$ satisfying $C \subset A(C), C \subset B(C)$ and $d(A x, B y) \geq h \min \{d(A x, x), d(B y, y), d(x, y)\}$ for all $x$, $y \in C$ with $x \neq y$ where $h>1$. Then $A$ or $B$ has a fixed point or $A$ and $B$ have a common fixed point.

PROOF. Note that $\varphi\left(t_{1}, t_{2}, t_{3}\right)=h \min \left\{t_{1}, t_{2}, t_{3}\right\}, h_{1}>1$ is in $\Phi^{*}$. Apply. Theorem $t$.

If $\mathrm{A}=\mathrm{B}$ in Corollary 3 we get a generalization of Theorem 3 in [9].

Boyd and Wong [10] call the collection of all real functions $\psi: \mathbb{R}^{+} \rightarrow \mathbb{R}^{+}$which satisfy the following conditions $\Psi$ :

$\left(\mathrm{C}_{4}\right) \psi$ is upper-semicontinuous and non-decreasing,

$\left(\mathrm{C}_{5}\right) \psi(\mathrm{t})<\mathrm{t}$ for cach $\mathrm{t}>0$.

THEOREM 8. Let $(\mathrm{X}, \mathrm{t}, \mathrm{d})$ be a d-complete symmetric Hausdorff topological space. If $\mathrm{A}$ and $B$ are continuous mappings from $C$, a closed subset of $X$, into $X$ such that $C \subset A(C)$, $\mathrm{C} \subset \mathrm{B}(\mathrm{C})$, and $\psi(\mathrm{d}(\mathrm{Ax}, \mathrm{By})) \geq \min \{\mathrm{d}(\mathrm{Ax}, \mathrm{x}), \mathrm{d}(\mathrm{By}, \mathrm{y}), \mathrm{d}(\mathrm{x}, \mathrm{y})\}$ for all $\mathrm{x}, \mathrm{y} \in \mathrm{C}$ where $\psi \in \Psi$ and $\sum_{n=0}^{\infty} \psi^{n}(\mathrm{t})<\infty$ for cach $\mathrm{t}>0$, then either $\mathrm{A}$ or $\mathrm{B}$ has a fixed point or $\mathrm{A}$ and $\mathrm{B}$ have a common fixed point.

PROOF. Let $\left\{\mathrm{x}_{n}\right\}_{n=0}^{\infty}$ be defined as in the proof of Theorem 6. If $\mathrm{x}_{n}=\mathrm{x}_{n+1}$ for some $\mathrm{n}$ then $\mathrm{A}$ or $\mathrm{B}$ has a fixed point. Suppose $\mathrm{x}_{n} \neq \mathrm{x}_{n+1}$ for all $\mathrm{n}$. Then

$$
\begin{aligned}
\psi\left(\mathrm{d}\left(\mathrm{x}_{2 n}, \mathrm{x}_{2 n+1}\right)\right) & =\psi\left(\mathrm{d}\left(\mathrm{Ax}_{2 n+1}, \mathrm{Bx}_{2 n+2}\right)\right) \\
& \geq \min \left\{\mathrm{d}\left(\mathrm{Ax}_{2 n+1}, \mathrm{x}_{2 n+1}\right), \mathrm{d}\left(\mathrm{Bx}_{2 n+2}, \mathrm{x}_{2 n+2}\right), \mathrm{d}\left(\mathrm{x}_{2 n+1}, \mathrm{x}_{2 n+2}\right)\right\} \\
& =\min \left\{\mathrm{d}\left(\mathrm{x}_{2 n}, \mathrm{x}_{2 n+1}\right), \mathrm{d}\left(\mathrm{x}_{2 n+1}, \mathrm{x}_{2 n+2}\right), \mathrm{d}\left(\mathrm{x}_{2 n+1}, \mathrm{x}_{2 n+2}\right)\right\} \\
& =\mathrm{d}\left(\mathrm{x}_{2 n+1}, \mathrm{x}_{2 n+2}\right)
\end{aligned}
$$

since $\psi(\mathrm{t})<\mathrm{t}$ for all $\mathrm{t}>0$.

Similarly, $\mathrm{d}\left(\mathrm{x}_{2 n+2}, \mathrm{x}_{2 n+3}\right) \leq \psi\left(\mathrm{d}\left(\mathrm{x}_{2 n+1}, \mathrm{x}_{2 n+2}\right)\right)$ and hence $\mathrm{d}\left(\mathrm{x}_{n+1}, \mathrm{x}_{n+2}\right) \leq \psi\left(\mathrm{d}\left(\mathrm{x}_{n}, \mathrm{x}_{n+1}\right)\right)$ for each $n$. Since $\psi$ is non-decreasing, $d\left(x_{n+1}, x_{n+2}\right) \leq \psi^{n}\left(d\left(x_{0}, x_{1}\right)\right)$. Now

$$
\sum_{n=0}^{\infty} \mathrm{d}\left(\mathrm{x}_{n}, \mathrm{x}_{n+1}\right) \leq \sum_{n=0}^{\infty} \psi^{n}\left(\mathrm{~d}\left(\mathrm{x}_{0}, \mathrm{x}_{1}\right)\right)<\infty
$$

The space $X$ is $d$-complete so there exists $p \in C$ such that $x_{n} \rightarrow p$ as $n \rightarrow \infty$. The mappings $A$ and $\mathrm{B}$ are continuous so $\mathrm{Ax}_{2 n+1}=\mathrm{x}_{2 n} \rightarrow \mathrm{Ap}$ and $\mathrm{Bx}_{2 n+2}=\mathrm{x}_{2 n+1} \rightarrow \mathrm{Bp}$. Limits are unique so $\mathrm{Ap}=\mathrm{p}=\mathrm{Bp}$.

\section{REFERENCES}

1. Troy L. Hicks and W. R. Crisler, A note on $T_{1}$ topologies, Proc. Amer. Math. Soc. 46 (1974), 94-96.

2. Troy L. Hicks, Fixed point theorems for d-complete topological spaces I, Int. J. Math. and Math. Sci. 15 (1992) 435-440.

3. Troy L. Hicks and B. E. Rhoades, Fixed point theorems for d-complete topological spaces II, Math. Japonica 37 (1992), 847-853.

4. Troy L. Hicks and B. E. Rhoades, Fixed points for pairs of mappings in d-complete topological spaces, Int. J. Math. \& Math. Sci. 16 No 2 (1993), 259-266. 
5. T. L. Hicks, Another view of fixed point theory, Math. Japonica 35 No 2 (1990) 231-234.

6. Troy L. Hicks and Linda Marie Saliga, Fixed point theorems for non-self maps I, Int. J. Math. and Math. Sci. 17 No 4 (1994), 713-716.

7. Shin Min Kang, Fixed points for expansive maps, Math, Japonica 38 No 4 (1993) 713-717.

8. M. A. Khan, M. S. Khan and S. Sessa, Some theorems on expansion mappings and their fixed points, Demonstratio Math. 19 (1986) 673-683.

9. Troy L. Hicks and Linda Marie Saliga, Fixed point theorems for non-self maps II, Math. Japonica 38 No 5 (1993), 953-956.

10. B. W. Boyd and J. S. W. Wong, on linear contractions, Proc. Amer. Math. Soc. 20 (1969) 458-464. 


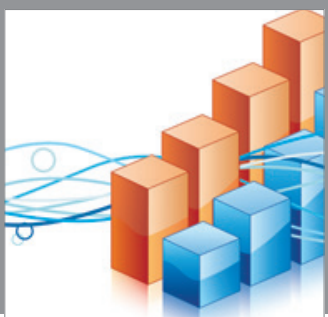

Advances in

Operations Research

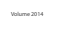

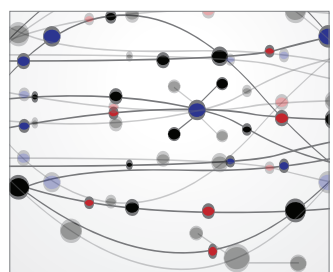

\section{The Scientific} World Journal
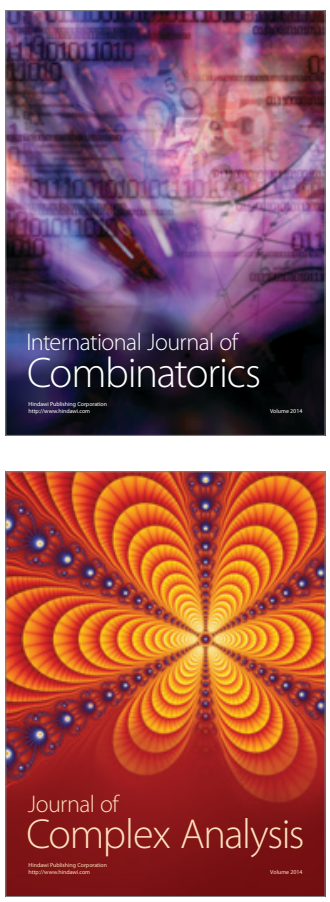

International Journal of

Mathematics and

Mathematical

Sciences
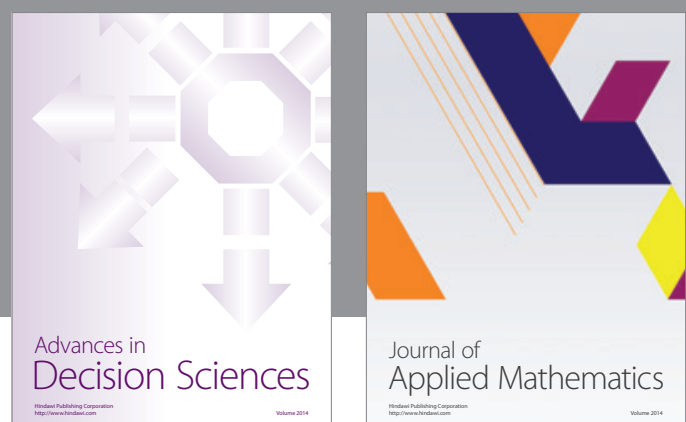

Journal of

Applied Mathematics
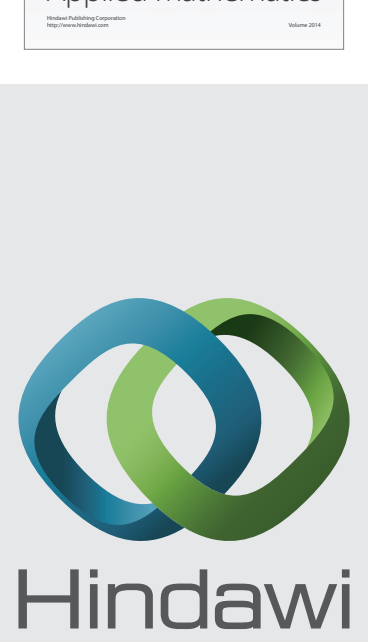

Submit your manuscripts at http://www.hindawi.com
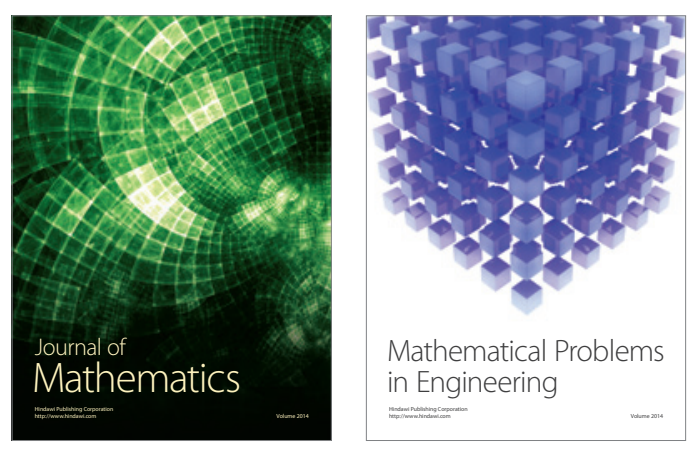

Mathematical Problems in Engineering
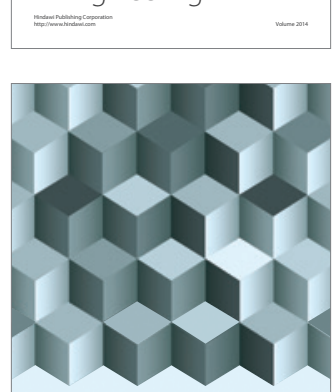

Journal of

Function Spaces
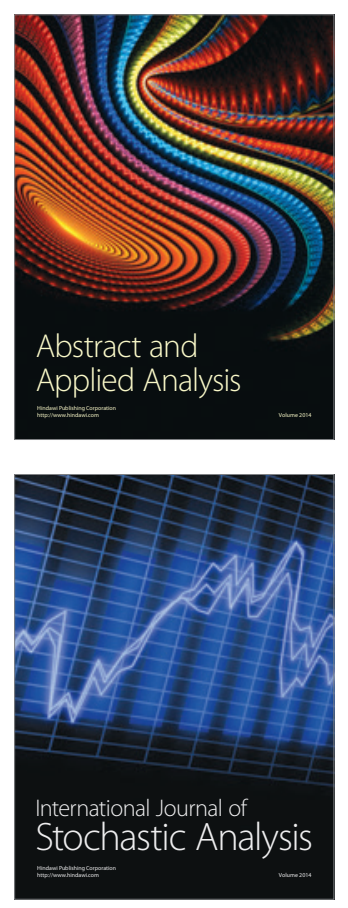

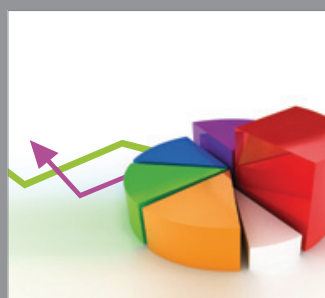

ournal of

Probability and Statistics

Promensencen
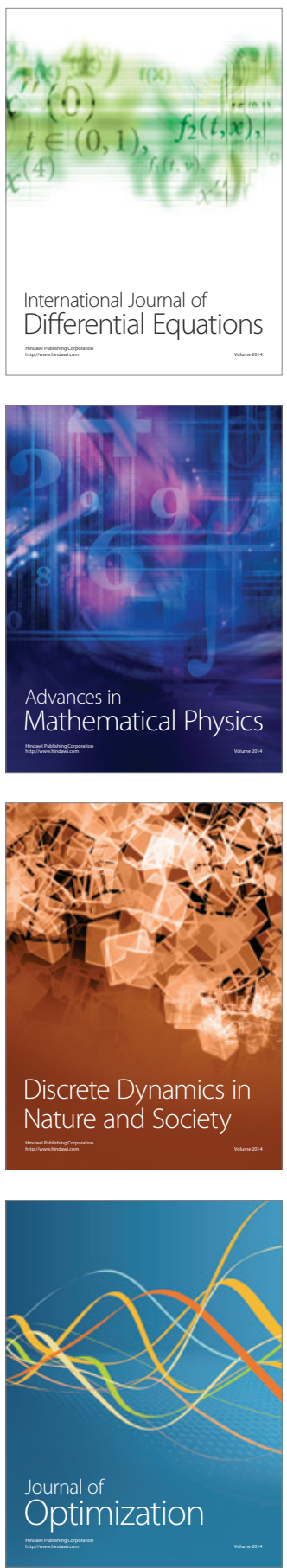